\title{
Effects of Multi-Stage Flash and Reverse Osmosis Desalinations on Benthic Assemblages in Bahrain, Arabian Gulf
}

\author{
Humood A. Naser \\ Department of Biology, College of Science, University of Bahrain, Sakhir, Kingdom of Bahrain. \\ Email: hnaser@uob.edu.bh
}

Received November $30^{\text {th }}, 2012$; revised December $24^{\text {th }}, 2012$; accepted January $21^{\text {st }}, 2013$

\begin{abstract}
Marine environment of the Arabian Gulf is naturally stressed due to marked fluctuations in sea temperatures and high salinities. Anthropogenically induced stresses including waste water discharges from desalination plants could pose additional threats to the coastal and marine ecosystems in the Arabian Gulf. Macrobenthic assemblages in the proximity of two major desalination plants that use Multi-Stage Flash (MSF) and brackish water Reverse Osmosis (RO) technologies in Bahrain were investigated. Reduced levels of biodiversity and abundance were recorded in sampling stations adjacent to the outlet of MSF reflecting severe impacts on macrobenthic assemblages caused by brine effluents that associated with high temperatures, salinities, and a range of chemical and heavy metal pollutants. Although localized severe impacts on macrobenthic assemblages were detected, collective discharges of desalination effluents, may synergistically contribute to the degradation of the naturally stressed marine ecosystems and natural resources in the Arabian Gulf.
\end{abstract}

Keywords: Macrobenthos; Nutrients; Metals; Brine Effluents; Bahrain; Arabian Gulf

\section{Introduction}

The Arabian Gulf countries are witnessing rapid industrial development and population growth, which increase the need for fresh water [1]. However, these countries are characterized by low precipitation and high aridity. Therefore, most of the fresh water needs in the Arabian Gulf countries are being obtained from seawater through the various processes of desalination, including MultiStage Flash (MSF), and seawater/brackish Reverse Osmosis (RO) [2]. It is estimated that the amount of desalinated water in the Arabian Gulf countries accounts for more than $60 \%$ of the world's total production [3].

Bahrain, like most of the Arabian Gulf countries, depends mainly on desalination seawater as a source of potable water with four major desalination plants (Table 1) [4]. All of the desalination plants in Bahrain are located on the eastern coastline of Bahrain. Nearly 79,250 $\mathrm{m}^{3}$ of effluents from these plants are being discharged into the marine environment on a daily basis. These effluents, including brine waters, are modified in their chemical and physical properties, which affect the seawaters' temperature and salinity and subsequently marine ecosystems [5].

The marine environment of the Arabian Gulf is natu- rally stressed due to marked fluctuations in sea temperatures and high salinities [6]. Its marine environment is considered among the highest anthropogenically impacted regions in the world [7]. Coastal development associated with intensive dredging and reclamation is contributing to the degradation of marine ecosystems. Further, several land-based activities such as oil refiners, sewage treatment plants, industrial facilities, and desalination plants are discharging effluents that contain a variety of contaminants.

Hypersaline water discharges associated with chemical products from desalination plants are increasingly becoming a serious threat to coastal and marine ecosystems in the Arabian Gulf [8]. Receiving marine environments are typically subject to chemical and physical alterations that can subsequently affect benthic communities. These changes include deterioration of seawater quality due to harmful chemical components including heavy metals, and anti-scaling, antifouling, antifoaming, and anticorrosion additive substances. Similarly, alterations in seawater temperature, dissolved oxygen and salt concentration may severely affect several marine organisms [9].

Macrobenthos are a species-rich group of invertebrates that mainly composed of polychaetes, crustaceans, molluscs, and many other taxonomic groups. Macrobenthic 
Table 1. Major desalination plants in Bahrain [4].

\begin{tabular}{ccccc}
\hline Plant & Operation date & Technology & ${\text { Water capacity gallon } \text { day }^{-1}}^{\text {Effluents }^{3} \cdot \text { day }^{-1}}$ \\
\hline Sitra power and water station & 1975 & Multi-stage flash & $25 \times 10^{6}$ & 66,000 \\
Ras Abu-Jarjur desalination plant & 1984 & Underground water reverse osmosis & $12 \times 10^{6}$ & 1500 \\
Addur desalination plant & 1990 & Seawater reserve osmosis & $10 \times 10^{6}$ & 3750 \\
Al-Hidd power and water station & 2000 & Multi-stage flash & $30 \times 10^{6}$ & 8000 \\
Total & & & 79,250 \\
\hline
\end{tabular}

assemblages are useful and sensitive indicators for the quality of intertidal and subtidal marine environments. These organisms consist of different species that show different levels of tolerance to stress and pollution. They can exhibit detectable changes in their community structure in response to disturbance such as changes in biodiversity, abundance, biomass, and numerical dominance of opportunistic species. Therefore, macrobenthic assemblages are widely used in ecological assessment and monitoring programmes [5]. Macrobenthic assemblages are increasingly utilized to characterize the effects of brine water discharges on marine environments, particularly in the Mediterranean [10-14]. However, such studies are extremely limited in the Arabian Gulf [15]. Therefore, the aim of this study was to assess the impacts of two desalination plants (MSF and brackish RO) on the abundance and biodiversity of macrobenthic assemblages inhabiting subtidal areas off the eastern coastline of Bahrain.

\section{Materials and Methods}

\subsection{Desalination Plants}

The study was conducted around Sitra Power and Water Station (SPWS) and Ras Abu-Jarjur Desalination Plant (RAJDP) in Bahrain (Figure 1). SPWS was the first multi-stage flash (MSF) desalination plant in Bahrain, which was commissioned in 1975. Fresh water in this station is obtained by applying thermal energy to the seawater feed in multiple stages creating a distillate of fresh water uses, and a concentrate brine stream that is returned to the sea. SPWS produces around 66,000 $\mathrm{m}^{3} \cdot$ day $^{-1}$ of effluents to the marine environment of which $12,000 \mathrm{~m}^{3}$ are brine water [16].

RAJDP produces around $46,000 \mathrm{~m}^{3} \cdot \mathrm{day}^{-1}$ of drinking quality water by desalinating high brackish groundwater based on the reverse osmosis technology. Brackish water form Ras-Umm Er Radhuma aquifer with a salinity ranges between 8 and $15 \mathrm{~g} \cdot l^{-1}$ is pumped at high pressure to special membranes forcing fresh water to flow through the membranes [17]. Approximately $1500 \mathrm{~m}^{3} \cdot$ day $^{-1}$ of concentrate remains are discharged to the marine environment [2].

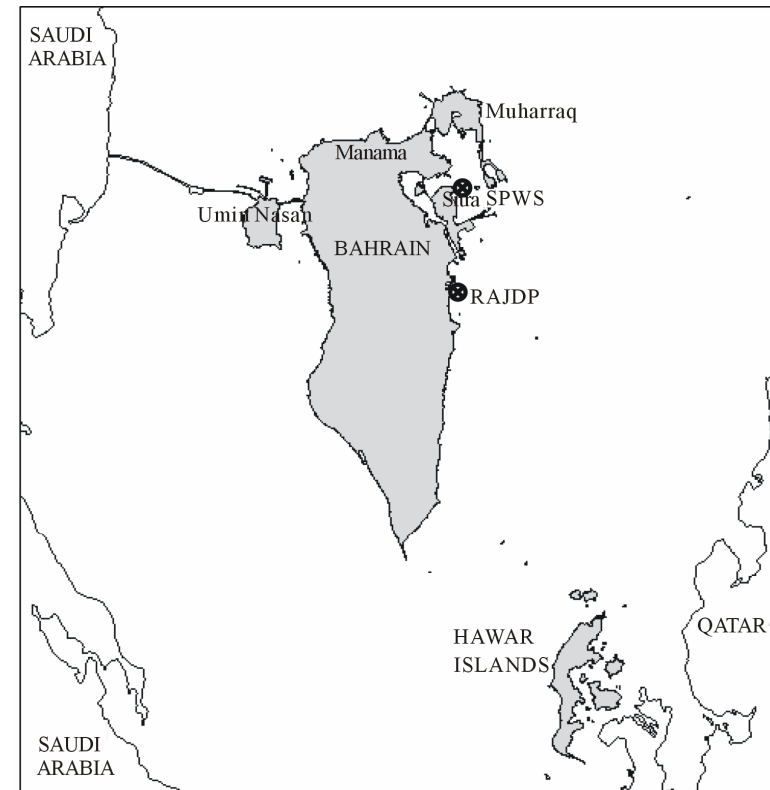

Figure 1. Map of Bahrain showing the location of the selected desolation plants; Sitra Power and Desalination Station (SPWS) and Ras Abu-Jarjur Desalination Plant RAJDP.

\subsection{Sampling Design}

Measurement and sampling were conducted subtidally in a transect design in order to detect the gradient impacts of the desalination plants on macrobenthic assemblages. The selected transects (hereinafter T1 and T2 for SPWS and RAJDP, respectively) were divided into eight stations with equal distance between each one $(200 \mathrm{~m})$. The first station of each transect was close to the discharge point as possible. Sampling was conducted in March 2012.

Although surveys to detect environmental disturbance require sampling over wide geographical regions and allocating of control sites [18], the utility of these designs in Bahrain are constrained by the lack of suitable control sites due coastal and marine developments that typically associated with intensive reclamation and dredging activities and land-based effluents [19]. Additionally, Bahrain marine environment is governed by variety of natural environmental factors that may interfere with the se- 
lection of control sites. For instance, salinities on the western coast of Bahrain are higher than those on the eastern coast by nearly $10 \%$, with average means of 50 57 and 43 - 45 PSU for the west and east coasts, respectively.

\subsection{Measurement of Environmental Parameters and Nutrients in Seawater}

Environmental parameters including depth (GARMIN FishFinder 240), Salinity (ATAGO refractometer), and water temperature were measured. Seawater samples were collected from a depth of $20 \mathrm{~cm}$, stored in a cold room at $0^{\circ} \mathrm{C}$ for $24 \mathrm{~h}$, and analyzed for nutrients; including ammonia, nitrate, and phosphate using a Palintest ${ }^{\circledR}$ photometer 8000 and proprietary assay kits.

\subsection{Sampling and Treatment of Macrobenthic Invertebrates}

Sediment samples were collected using Van Veen grab $\left(0.0675 \mathrm{~m}^{2}\right)$. Four grabs were collected in each stations; three replicates for macrobenthic invertebrates and one grab for grain size analysis of the sediment as well as analysis of selected heavy metals. Faunal samples were sieved in situ through a $1.0 \mathrm{~mm}$ mesh using seawater, fixed in $4 \%$ formalin, stained with drops of rose Bengal and subsequently preserved in $70 \%$ ethyl alcohol. Organisms were sorted according to their taxonomic groups, counted and identified to the lowest possible taxonomic resolution using relevant identification guides. The ashfree biomass was determined for each taxon per sample using muffle furnace (Thermolyne 6000 Furnace) at a temperature of $450^{\circ} \mathrm{C}$ for $8 \mathrm{~h}$.

\subsection{Sediment Analyses}

Sediment samples were analyzed physically (organic content and grain size analysis), and chemically (sediment digestion and analysis of the selected heavy metals). Sediment grain size analysis was conducted by sieving $50 \mathrm{~g}$ of homogenized sediment on a mechanical shaker (KARL KOB) through six sieves (mesh sizes 0.038 - 2 $\mathrm{mm}$ ) and obtaining weight of sediment fraction in each sieve. The percentage of organic content the sediment was obtained by incinerating a known weight at a temperature of $450^{\circ} \mathrm{C}$ for $12 \mathrm{~h}$. Microwave-assisted digestion was conducted using a microwave (ETHOS D). The digestion was performed using $10 \mathrm{ml}$ of nitric acid following to USEPA 3051 methods. The samples were analyzed for zinc, cadmium, lead, and copper using atomic absorption spectrometer (A Analyst 100).

\subsection{Statistical Analysis}

Univariate and multivariate analyses were employed to test for differences between the two transects. Ecological indices including diversity index of Shannon-Wiener, Margalef's index of richness and Pielou's index of evenness were calculated. The spatial variation of macrobenthic assemblages was analysed by non-metric multidimensional scaling (nm-MDS) based on Bray-Curtis similarity index using square-root transformed abundance data. The degree of disturbance was assessed using abundance/biomass comparison (ABC) and associated W statistic value, which was standardized and incorporated onto the faunal MDS. ABC technique is based on the differential response in the distribution of number and biomass of individuals among species due to pollution and disturbance. Therefore, this technique may potentially detect the environmental conditions of the selected site without reference to control or unimpacted areas [20]. Environmental factors were analyzed based on Euclidean distance similarity measure. Environmental variables best correlated with patterns of macrobenthic assemblages were identified using Spearman coefficient (BIOENV analysis). Tests were carried out using PRIMER $^{\circledR} \mathrm{v}$ 6 [21].

\section{Results}

\subsection{Environmental Parameters}

Significant variations in the environmental factors were detected among the stations of the two transects (ANOSIM R $=0.297, \mathrm{P}=0.001$ ). T1 is relatively deeper than T2 $(9.5 \pm 3.8$ and $4.4 \pm 1.9 \mathrm{~m}$, respectively). Sediments were characterized as medium sand $(\varnothing=1.45 \pm$ $1.35)$ and fine sand $(\varnothing=2.13 \pm 0.55)$ for $\mathrm{T} 1$ and $\mathrm{T} 2$, respectively. Concentrations of ammonia and phosphate were higher in $\mathrm{T} 1\left(1.28 \pm 2.4\right.$ and $\left.0.26 \pm 0.17 \mathrm{mg} \cdot l^{-1}\right)$ than T2 $\left(0.09 \pm 0.12\right.$ and $\left.0.05 \pm 0.02 \mathrm{mg} \cdot 1^{-1}\right)$, respectively. Zinc and copper exhibited higher levels of concentration in $\mathrm{T} 1\left(57.70 \pm 16.1\right.$ and $27.90 \pm 4.8 \mathrm{mg} \cdot \mathrm{kg}^{-1}$, respectively). Conversely, lead and cadmium concentrations were higher in T2 $(23.9 \pm 8.0$ and $1.29 \pm 2.6$ $\mathrm{mg} \cdot \mathrm{kg}^{-1}$, respectively). Environmental measurements of physical and chemical parameters are presented in Table 2.

MDS (Figure 2) revealed that stations of T2 (apart from station 1 of the same transect) were clustering together indicating a higher level of similarity between these stations. Conversely, stations 1 - 4 of T1 were scattered over the MDS. In particular, station one of T1 showed a higher level of dissimilarity with the rest of stations, which could be attributed to the high levels of salinity, nutrients and heavy metals.

\subsection{Macrobenthic Assemblages}

Differences in macrobenthic community structure were detected between $\mathrm{T} 1$ and $\mathrm{T} 2$. A total of 371 individual 
Table 2. Environmental parameters, including nutrients and heavy metal analyses, for stations (1 - 8) off Sitra Power and Water Station (SPWS) and Ras Abu-Jarjur Desalination Plant (RAJDP).

\begin{tabular}{|c|c|c|c|c|c|c|c|c|c|c|c|c|c|c|c|c|}
\hline \multirow[b]{2}{*}{$\begin{array}{l}\text { Environmental } \\
\text { parameters }\end{array}$} & \multicolumn{8}{|c|}{ SPWS (MSF) } & \multicolumn{8}{|c|}{ RAJDP (RO) } \\
\hline & 1 & 2 & 3 & 4 & 5 & 6 & 7 & 8 & 1 & 2 & 3 & 4 & 5 & 6 & 7 & 8 \\
\hline Depth (m) & 5.0 & 1.1 & 0.9 & 3.3 & 7.5 & 10.8 & 9.9 & 8.3 & 1.3 & 1.9 & 4.0 & 5.0 & 5.5 & 5.3 & 5.9 & 6.4 \\
\hline Water Temp. ${ }^{\circ} \mathrm{C}$ & 35 & 27 & 21 & 21 & 21 & 21 & 21 & 21 & 21 & 21 & 21 & 21 & 21 & 21 & 21 & 21 \\
\hline Salinity (PSU) & 48 & 46 & 45 & 45 & 45 & 45 & 45 & 45 & 45 & 45 & 45 & 45 & 45 & 46 & 46 & 46 \\
\hline$\%$ Organic content & 1.20 & 1.90 & 2.10 & 2.67 & 4.03 & 4.70 & 6.36 & 4.71 & 3.96 & 5.90 & 4.24 & 3.55 & 2.19 & 2.93 & 3.82 & 3.91 \\
\hline $\begin{array}{l}\text { Mean sediment } \\
\text { particle }(\varnothing)\end{array}$ & 0.20 & 0.21 & 0.21 & 0.23 & 2.66 & 2.77 & 3.19 & 2.10 & 2.23 & 2.24 & 2.25 & 1.08 & 1.68 & 2.07 & 2.78 & 2.71 \\
\hline \multicolumn{17}{|l|}{ Nutrients $\left(\mathrm{mg} \cdot \mathrm{l}^{-1}\right)$} \\
\hline Ammonia & 6.10 & 4.02 & 0.01 & 0.01 & 0.01 & 0.00 & 0.00 & 0.06 & 0.37 & 0.09 & 0.00 & 0.07 & 0.04 & 0.00 & 0.01 & 0.10 \\
\hline Nitrate & 0.76 & 0.85 & 0.90 & 0.01 & 0.55 & 1.00 & 0.90 & 0.90 & 0.58 & 0.70 & 0.50 & 0.60 & 1.00 & 0.90 & 0.53 & 0.75 \\
\hline Phosphate & 0.48 & 0.22 & 0.24 & 0.12 & 0.55 & 0.20 & 0.16 & 0.07 & 0.04 & 0.04 & 0.03 & 0.02 & 0.07 & 0.07 & 0.10 & 0.03 \\
\hline
\end{tabular}

Heavy metals $\left(\mathrm{mg} \cdot \mathrm{kg}^{-1}\right)$

\begin{tabular}{ccccccccccccccccc} 
Zinc & 68.45 & 44.65 & 48.56 & 29.08 & 57.46 & 69.42 & 78.59 & 65.36 & 38.80 & 33.94 & 60.88 & 39.34 & 34.95 & 41.44 & 34.27 & 37.44 \\
Cadmium & 3.36 & 0.64 & 0.38 & 0.38 & 0.08 & 0.46 & 1.68 & 0.64 & 7.64 & 0.45 & 0.65 & 0.21 & 0.33 & 0.22 & 0.22 & 0.58 \\
Lead & 12.91 & 13.22 & 14.27 & 8.60 & 13.55 & 17.75 & 15.10 & 16.74 & 33.28 & 29.36 & 34.58 & 22.15 & 21.08 & 18.68 & 15.16 & 13.62 \\
Copper & 36.70 & 22.65 & 22.80 & 28.35 & 24.84 & 29.31 & 31.98 & 26.53 & 11.62 & 11.75 & 17.32 & 12.86 & 12.36 & 15.79 & 13.12 & 14.42 \\
\hline
\end{tabular}

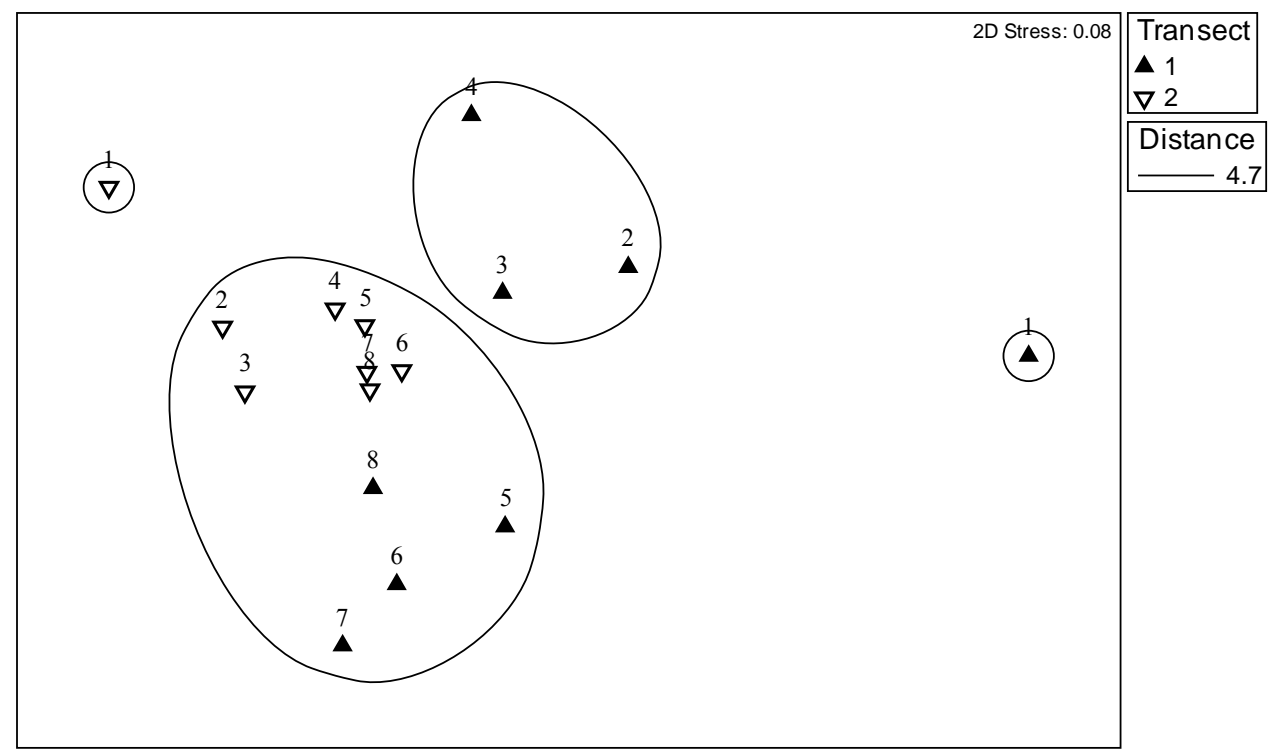

Figure 2. MDS of normalized environmental measurements using Euclidian distance. ANOSIM R = 0.297, $P=0.001$.

organisms belonging to 43 species were recorded in the stations of T1 compared with 1403 individual organisms belonging to 75 species in T2 (Table 3). Polychaetes were the most abundant among the major taxonomic groups in $\mathrm{T} 1$ representing $47 \%$ the benthos population followed by crustaceans $45 \%$, molluscs $7 \%$, and cnidarians $1 \%$. In T2, polychaetes were also the most abundant group representing $68 \%$ of the population followed by molluscs $25 \%$, crustaceans $6 \%$, and sipunculid worms $1 \%$. Ecological indices namely, Shannon-Wiener diversity, species richness and evenness were higher in T2 compared with T1 (Figure 3).

The MDS of faunal abundance revealed a clear separation between samples collected from T1 and T2 (Figure 4) 
Table 3. Ecological indices of faunal assemblages collected from stations (1 - 8) off Sitra Power and Water Station (SPWS) and Ras Abu-Jarjur Desalination Plant (RAJDP).

\begin{tabular}{cccccccccccccccccccccc}
\hline & \multicolumn{1}{c}{ SPWS (MSF) } & \multicolumn{1}{c}{ RAJDP (RO) } \\
\hline & 1 & 2 & 3 & 4 & 5 & 6 & 7 & 8 & 1 & 2 & 3 & 4 & 5 & 6 & 7 & 8 \\
Number of species & 4 & 5 & 8 & 10 & 10 & 9 & 5 & 9 & 20 & 17 & 16 & 24 & 25 & 23 & 19 & 18 \\
Number of organisms $0.02 \mathrm{~m}^{-2}$ & 28 & 30 & 28 & 29 & 85 & 101 & 11 & 59 & 201 & 156 & 126 & 259 & 197 & 230 & 86 & 178 \\
Species richness & 0.90 & 1.18 & 2.10 & 2.67 & 2.03 & 1.73 & 1.67 & 1.96 & 3.58 & 3.17 & 3.10 & 4.14 & 4.54 & 4.05 & 4.04 & 3.40 \\
Species evenness J' & 0.75 & 0.75 & 0.81 & 0.91 & 0.83 & 0.54 & 0.85 & 0.77 & 0.65 & 0.79 & 0.80 & 0.82 & 0.79 & 0.80 & 0.81 & 0.72 \\
Diversity H' (loge) & 1.04 & 1.21 & 1.68 & 2.10 & 1.92 & 1.18 & 1.37 & 1.70 & 1.95 & 2.23 & 2.22 & 2.60 & 2.55 & 2.50 & 2.39 & 2.07 \\
\hline
\end{tabular}

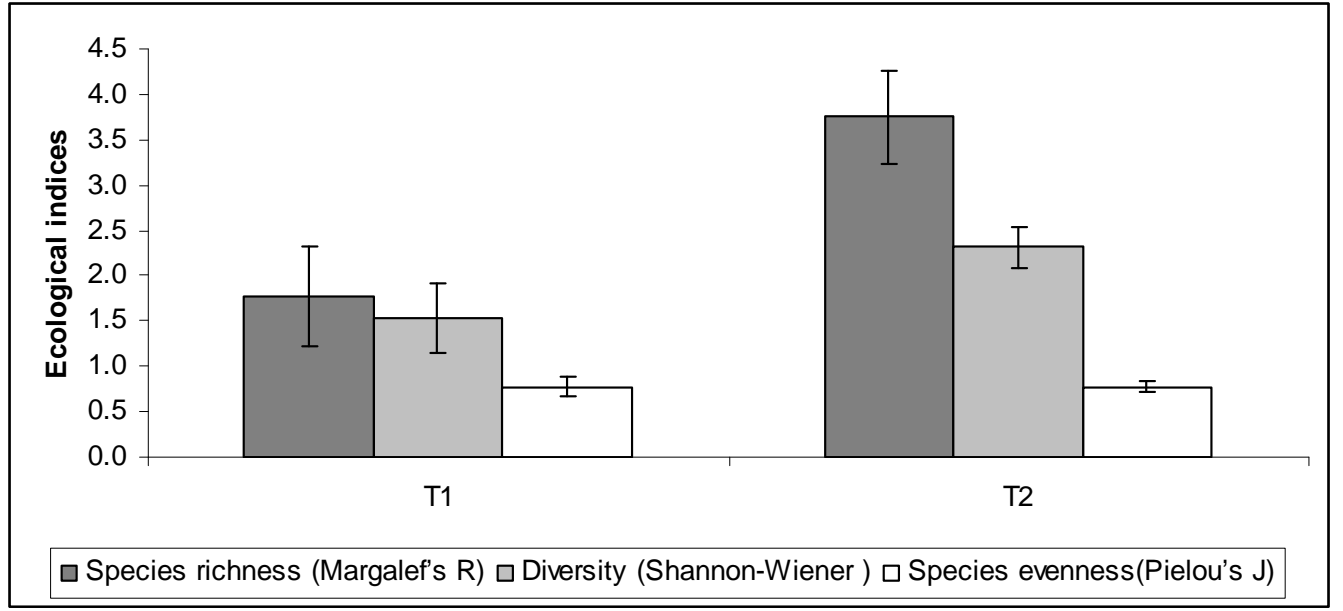

Figure 3. Ecological indices represented by Shannon-Wiener diversity, species richness and evenness in T1 and T2.

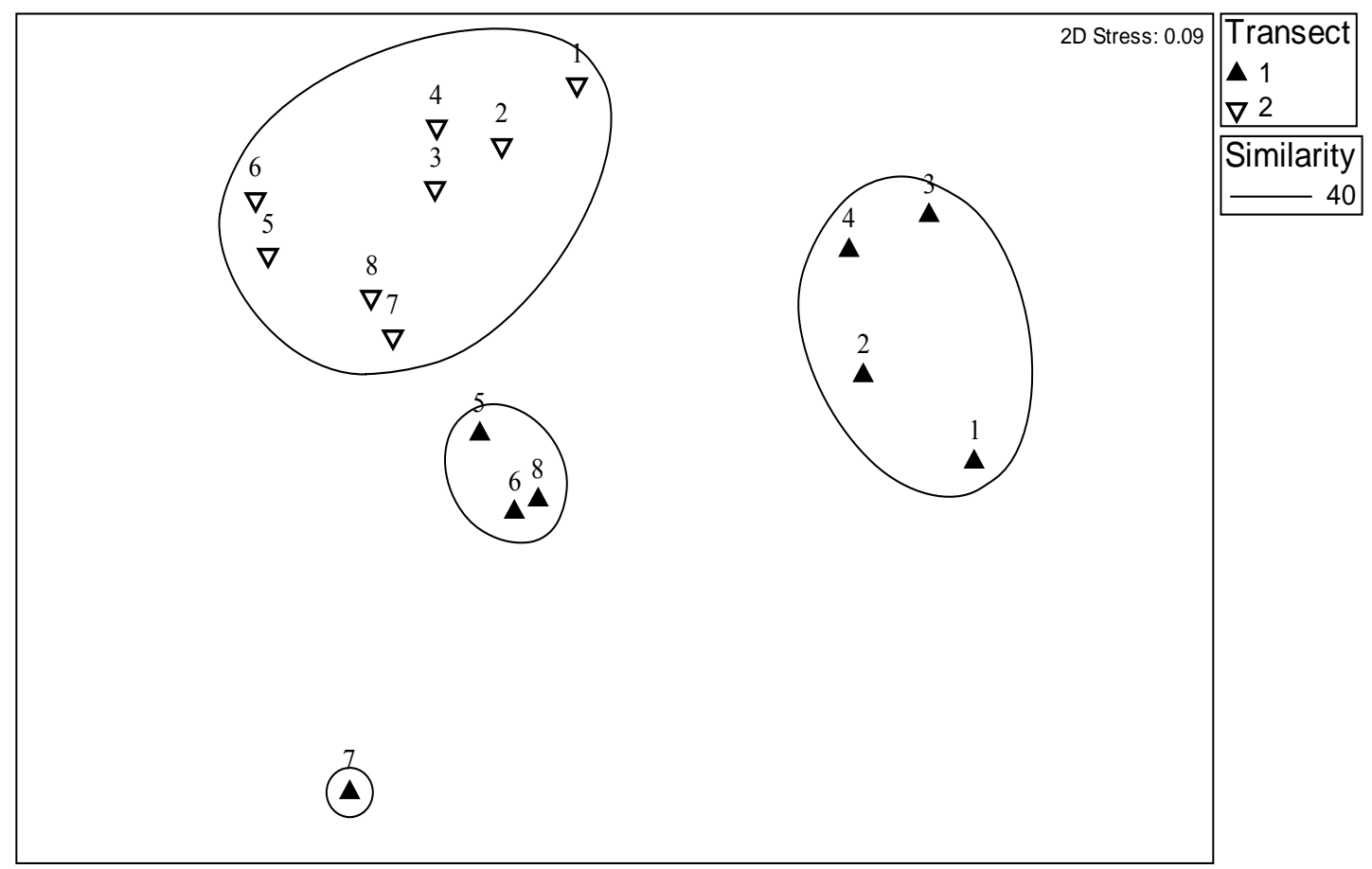

Figure 4. MDS plot for square-root transformed faunal abundance using Bray-Curtis similarity coefficient. Resemblance matrices were clustered to generate similarity of $40 \%$ on the MDS. ANOSIM R $=0.549, P=0.001$. 
suggesting pronounced differences in their community structure (ANOSIM: $\mathrm{R}=0.541, \mathrm{P}=0.001$ ). Stations of $\mathrm{T} 2$ were clustering together indicating a higher level of similarity between their community structure. Conversely, stations of T1 exhibited distinctive dissimilarities with three groups separated by $40 \%$ similarity; stations $1-4$, stations 5, 6 and 8, and station 7 .

Comparison of standardized $\mathrm{W}$ statistic values associated with $\mathrm{ABC}$ curves of stations revealed a clear trend of increasing degree of disturbance towards the outlet in T1. However, no clear onshore-offshore trend of disturbance was clearly detected in T2 (Figure 5).

BIOENV analysis for correlations between the faunal assemblages and associated environmental parameters indicated that $42 \%$ of the biota patterns were explained by a combination of depth, sediment grain particle and copper concentration.

\section{Discussion}

Waste water discharges form desalination processes may alter physically and chemically the characteristics of receiving seawater, including water temperature and salinity [3,22]. Differences of $5^{\circ} \mathrm{C}$ to $15^{\circ} \mathrm{C}$ above ambient seawater temperature have been reported near the outlet mixing zone of MSF desalination plants [23]. Similarly, the present study recorded a difference of $14^{\circ} \mathrm{C}$ above the ambient seawater temperature in approximately $400 \mathrm{~m}$ from the outlet of SPWS. Temperature of reject water from RO desalination plants is typically close to ambient sweater temperature [24], which was confirmed in the present study near the outlet of RAJDP.

Thermal desalination processes, including MSF account for $90 \%$ of the production in the Arabian Gulf

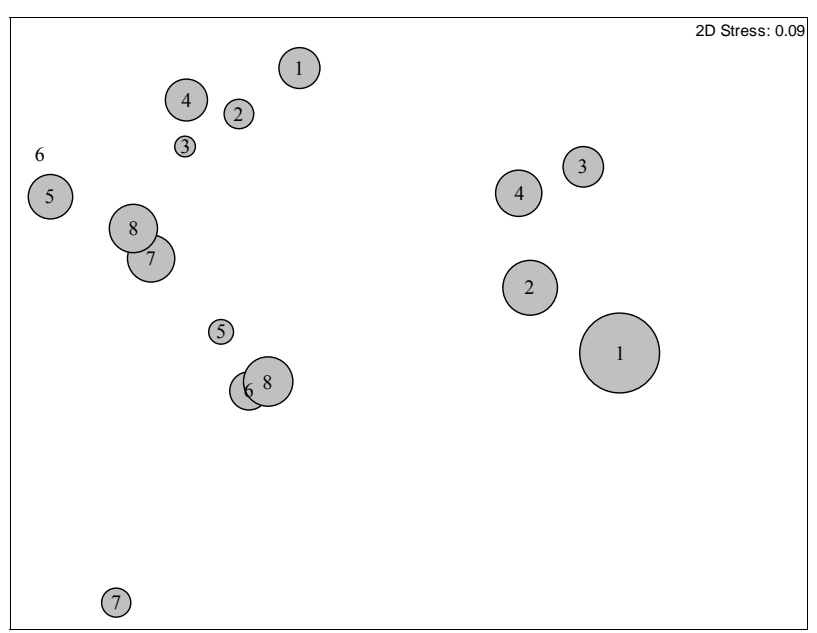

Figure 5. Bubble plots for standardized $W$ statistic values on the faunal abundance MDS showing the degree of disturbance in each station; the larger the bubble the greater the disturbance. countries [24], which could contribute to the fluctuations of seawater temperature. This has several implications on the integrity of marine ecosystems in the light of climatic change events, which are frequently increasing in the Arabian Gulf [6].

Increased salinity around desalination outlets is attributed to high temperature due to cooling water and consequent evaporation, and high concentration of salts associated with discharge water. Salinity has a profound effect on abundance and composition of macrobenthic assemblages [25]. Additionally, an increase in salt concentration immediately adjacent to any brine outlet may result in physiological stress on several species and their larvae [26,27]. For instance, evidences of salinity stress such as lower rate of leaf growth and increased leaf necrosis as a result of brine discharge off the Spanish coast have been reported [28]. A difference of 3 PSU above ambient seawater salinity near SPWS was recoded. Conversely, salinity near RAJDP was close to ambient sweater salinity, which could be attributed to the relatively low salinity concentration of the feed water from the aquifer.

Several studies suggested that biota in the Arabian Gulf are living on the extreme limits of their environmental tolerance due to marked fluctuations in sea temperatures and high salinities [29]. Salinity in the Arabian Gulf can exceed 43 PSU and could reach 70 - 80 PSU in areas with restricted flow such as tidal pools and lagoons due to high evaporation rates. Installation of more power and desalination plants in the Arabian Gulf is expected to increase in the coming future [30], which may result in cumulative impacts from the brine discharges leading to substantial fluctuations in salinity levels. Indeed, some studies forecasted that brine discharge will increase the salinity of the Arabian Gulf by $2.24 \mathrm{~g} \cdot \mathrm{l}^{-1}$ in 2050 [31], which could arguably be critical to the naturally stressed marine ecosystems in the Arabian Gulf.

Heavy metals are considered by-product from desalination processes due corrosion [24]. Copper, nickel and zinc alloys are common materials for heat exchanger surfaces in MSF desalination process. This was reflected in the higher concentrations of copper and zinc recorded near the outlet of SPWS. Mean concentrations of cadmium and lead were found higher off RAJDP. However, hydrocarbons and petroleum industries that heavily occupied the eastern coastline might contribute to the overall load of heavy metals due to continuous discharge of industrial effluents to nearby subtidal areas [32-34].

Alterations in abundance, diversity and composition in macrobenthic assemblages at proximity to brine discharge outlets have been reported [35]. Reduced levels of biodiversity and abundance were recorded in sampling stations adjacent to the outlet of SPWS reflecting severe 
impacts on macrobenthic assemblages caused by brine effluents, which are associated with high temperatures, salinities, and a range of chemical and heavy metal pollutants (Table 3). The first four stations of T1 were characteristically distinguished from the rest of stations. High levels of disturbance represented by $\mathrm{W}$ statistics were detected nearby the outlet of SPWS (Figure 5). Conversely, Brackish RO appeared to have limited impacts of the macrobenthic assemblage in comparison with the MSF represented by high levels of abundance and biodiversity (Table 2 ).

Depth and sediment characteristics are major factors in governing the spatial distribution of marine benthos in the Arabian Gulf. A combination of the natural environmental factors (i.e. depth and sediment grain particle), and anthropogenic copper load explained $42 \%$ of the community patterns of macrobenthic assemblages in the study area.

Adverse environmental effects may result not from the direct effects of a particular project, but from the combination and interaction of individually minor effects of multiple projects over time [24]. Even though this study revealed only localized severe impacts on macrobenthos at the proximity of brine discharge outlet, desalination plants in Bahrain my synergistically affect coastal and marine ecosystems as most of the desalination plants are located on the eastern coastline in Bahrain. These plants are collectively discharging large quantities of waste water to the shallow subtidal areas off the eastern coastline that support sensitive ecosystems including mangroves, seagrass beds, and coral reefs [16]. Therefore, further studies to investigate the holistic impact of desalinations on marine environment in the Arabian Gulf are critically required. This should involve physical, chemical, and biological aspects of environmental monitoring. Additionally, enforcing environmental regulations related to pollution from land-based activities, including desalination plants, could contribute to the protection of marine ecosystems. Environmental Impact Assessment (EIA) should be applied to proposed desalination plant projects in order to optimize their environmental impacts on the marine ecosystems. Similarly, water policy and strategic framework for water resources management that address environmental concerns of desalination sector on coastal and marine environments of the Arabian Gulf are urgently required.

\section{Acknowledgements}

Logistical support provided by the Department of Biology, College of Science, University of Bahrain, and the General Directorate of Marine Resources at the Ministry of Municipalities and Urban Planning in Bahrain is highly appreciated. Assistance provided by Mr. Sami
Abdulla during sampling is gratefully acknowledged. Thanks are also due to Mrs. Fatima Al-Ammari for her technical assistance.

\section{REFERENCES}

[1] R. Smith, A. Purnama and H. Al-Barwani, "Sensitivity of Hypersaline Arabian Gulf to Seawater Desalination Plants," Applied Mathematical Modeling, Vol. 31, No. 10, 2007, pp. 2347-2354. doi:10.1016/j.apm.2006.09.010

[2] A. Hashim and M. Hajjaj, "Impact of Desalination Plants Fluid Effluents on Integrity of Seawater, with the Arabian Gulf in Perspective," Desalination, Vol. 182, No. 1-3, 2005, pp. 373-393. doi:10.1016/j.desal.2005.04.020

[3] S. Lattemann and T. Hoepner, "Environmental Impact and Impact Assessment of Seawater Desalination," Desalination, Vol. 220, No 1-3, 2008, pp. 1-15.

[4] A. Khalaf and M. Redha, "Rehabilitation of Water Production Facilities of the Ministry of Electricity and Water, State of Bahrain," Desalination, Vol. 138, No. 1-3, 2001, pp. 319-328. doi:10.1016/S0011-9164(01)00280-6

[5] H. Naser, "Using Macrobenthos as Tool for Ecological Impact Assessment: Application in Environmental Impact Assessment (EIA)," Lambert Academic Publishing, Saarbrucken, 2010.

[6] C. Sheppard, M. Al-Husiani, F. Al-Jamali, F. Al-Yamani, R. Baldwin, J. Bishop, F. Benzoni, E. Dutrieux, N. Dulvy, S. Durvasula, D. Jones, R. Loughland, D. Medio, M. Nithyanandan, G. Pilling, I. Polikarpov, A. Price, S. Purkis, B. Riegl, M. Saburova, K. Namin, O. Taylor, S. Wilson and K. Zainal, "The Gulf: A Young Sea in Decline," Marine Pollution Bulletin, Vol. 60, No. 1, 2010, pp. 3-38. doi:10.1016/j.marpolbul.2009.10.017

[7] B. Halpern, S. Walbridge, K. Selkoe, C. Kappel, F. Micheli, C. D’Agrosa, J. Bruno, K. Casey, C. Ebert, H. Fox, R. Fujita, D. Heinemann, H. Lenihan, E. Madin, M. Perry, E. Selig, M. Spalding, R. Steneck and R. Watson, "A Global Map of Human Impact on Marine Ecosystems," Science, Vol. 319, No. 5865, 2008, pp. 948-952. doi:10.1126/science. 1149345

[8] A. Areiqat and K. Mohamed, "Optimization of the Negative Impact of Power and Desalination Plants on the Ecosystem," Desalination, Vol. 185, No. 1-3, 2005, pp. 95103. doi:10.1016/j.desal.2005.04.038

[9] D. Roberts, E. Johnston and N. Knott, "Impacts of Desalination Plant Discharges on the Marine Environment: A Critical Review of Published Studies," Water Research, Vol. 44, No. 18, 2010, pp. 5117-5128.

doi:10.1016/j.watres.2010.04.036

[10] N. Raventos, E. Macpherson and A. Garcia-Rubies, "Effect of Brine Discharge from Desalination Plant on Macrobenthic Communities in the NW Mediterranean," Marine Environmental Research, Vol. 62, No. 1, 2006, pp. 1-14. doi:10.1016/j.marenvres.2006.02.002

[11] Y. Ruso, J. Carretero, F. Casalduero and J. Lizaso, "Spatial and Temporal Changes in Infaunal Communities Inhabiting Softbottoms Affected by Brine Discharge," Marine Environmental Research, Vol. 64, No. 4, 2007, pp. 
492-503. doi:10.1016/j.marenvres.2007.04.003

[12] Y. Ruso, J. Carretero, F. Casalduero and J. Lizaso, "Effects of a Brine Discharge over Soft Bottom Polychaeta Assemblage," Environmental Pollution, Vol. 156, No. 2, pp. 2008, pp. 240-250.

[13] Y. Ruso, J. Carretero, A. Fernandez, L. Vicente, F. Casalduero and J. Lizaso, "Assessment of Soft-Bottom Polychaeta Assemblage Affected by a Spatial Confluence of Impacts: Sewage and Brine Discharges," Marine Pollution Bulletin, Vol. 58, No. 5, 2009, pp. 765-786.

[14] R. Riera, F. Tuya, E. Ramos, M. Rodriguez and O. Monterroso, "Variability of Macrofaunal Assemblages on the Surrounding of a Brine Disposal," Desalination, Vol. 291, 2012, pp. 94-100. doi:10.1016/j.desal.2012.02.003

[15] H. Naser, “Testing Taxonomic Resolution Levels for Detecting Environmental Impacts Using Macrobenthic Assemblages in Tropical Waters," Environmental Monitoring and Assessment, Vol. 170, No. 1-4, 2010, pp. 435444. doi:10.1007/s10661-009-1244-7

[16] H. Naser, "Human Impacts on Marine Biodiversity: Macrobenthos in Bahrain, Arabian Gulf," In: J. Lopez-Pujol, Ed., The Importance of Biological Interactions in the Study of Biodiversity, InTech Publishing, Croatia, 2011, pp. 109-126. doi:10.5772/23046

[17] W. Al-Zubari, "Assessing the Sustainability of Non-Renewable Brackish Groundwater in Feeding an RO Desalination Plant in Bahrain," Desalination, Vol. 159, No. 3, 2003, pp. 211-224. doi:10.1016/S0011-9164(03)90074-9

[18] A. Underwood, "On beyond BACI: Sampling Designs that Might Reliably Detect Environmental Disturbance," Ecological Applications, Vol. 4, No. 1, 1994, pp. 3-15. doi: $10.2307 / 1942110$

[19] K. Zainal, I. Al-Madany, H. Al-Sayed, A. Khamis, S. Al-Shuhaby, A. Al-Hisaby, W. Elhoussiny and E. Khalaf, "The Cumulative Impacts of Reclamation and Dredging on the Marine Ecology and Land-Use in the Kingdom of Bahrain," Marine Pollution Bulletin, Vol. 64, No. 7, 2012, pp. 1452-1458. doi:10.1016/j.marpolbul.2012.04.004

[20] R. Warwick, "A New Method for Detecting Pollution Effects on Marine Macrobenthic Communities," Marine Biology, Vol. 92, No. 4, 1986, pp. 557-562. doi:10.1007/BF00392515

[21] K. Clarke and R. Gorley, "PRIMER v6: User manual tutorial," PRIMER-E. Plymouth, 2006.

[22] T. Hoepner, "A Procedure for Environmental Impact Assessment (EIA) for Seawater Desalination Plants," Desalination, Vol.124, 1999, pp. 1-12. doi:10.1016/S0011-9164(99)00083-1

[23] A. Altayaran and I. Madany, "Impact of a Desalination Plant on the Physical and Chemical Properties of Seawater, Bahrain," Water Research, Vol. 26, No. 4, 1992, pp. 435-441. doi:10.1016/0043-1354(92)90043-4

[24] S. Lattemann and T. Hopner, "Impacts of Seawater Desalination Plants on the Marine Environment of the Gulf, In: A. Abuzinada, H. Barth, F. Krupp, B. Boer and T.
Abdessalaam, Eds., Protecting the Gulf's Marine Ecosystems from Pollution, Birkhauser, Berlin, pp. 191-205.

[25] C. Joyce, C. Vina-Herbon and D. Metcalfe, "Biotic Variation in Coastal Water Bodies in Sussex, England: Implications of Saline Lagoons," Estuarine, Coastal and Shelf Sciences, Vol. 65, No. 4, 2005, pp. 633-644. doi:10.1016/j.ecss.2005.07.006

[26] R. Einav, K. Harussi and K. Perry, "The Footprint of the Desalination Processes on the Environment," Desalination, Vol. 152, No. 1-3, 2002, pp. 141-154. doi:10.1016/S0011-9164(02)01057-3

[27] R. Miri and A. Chouikhi, "Ecotoxicological Marine Impacts from Seawater Desalination Plants," Desalination, Vol. 182, No. 1-3, 2005, pp. 403-410. doi:10.1016/j.desal.2005.02.034

[28] E. Gacia, O. Invers, M. Manzanera, E. Ballesteros and J. Romero, "Impact of the Brine from a Desalination Plant on a Shallow Seagrass (Posidonia oceanica) Meadow," Estuarine, Coastal and Self Science, Vol. 72, No. 4, 2007, pp. 579-590. doi:10.1016/j.ecss.2006.11.021

[29] A. Price, "Simultaneous Hotspots and Coldspots of Marine Biodiversity and Implications for Global Conservation," Marine Ecology Progress Series, Vol. 241, 2002, pp. 23- 27. doi: $10.3354 /$ meps 241023

[30] M. Dawoud, "The Role of Desalination in Augmentation of Water Supply in GCC Countries," Desalination, Vol. 186, No. 1-3, 2005, pp. 187-198. doi:10.1016/j.desal.2005.03.094

[31] R. Bashitialshaaer, K. Persson and M. Aljaradin, "Estimated Future Salinity in the Arabian Gulf, the Mediterranean Sea and the Red Sea Consequences of Brine Discharge from Desalination," International Journal of Academic Research, Vol. 3, 2011, pp. 133-140.

[32] S. De Mora, S. Fowler, E. Wyse and S. Azemard, "Distribution of Heavy Metals in Marine Bivalves, Fish and Coastal Sediments in the Gulf and Gulf of Oman," Marine Pollution Bulletin, Vol. 49, 2004, pp. 410-424. doi:10.1016/j.marpolbul.2004.02.029

[33] S. De Mora, I. Tolosa, S. Fowler, J. Villeneuve, R. Cassi and C. Cattini, "Distribution of Petroleum Hydrocarbons and Organochlorinated Contaminants in Marine Biota and Coastal Sediments from the ROPME Sea Area during 2005," Marine Pollution Bulletin, Vol. 60, No. 5-6, 2010, pp. 2323-2349. doi:10.1016/j.marpolbul.2010.09.021

[34] H. Naser, "Metal Concentrations in Marine Sediments Influenced by Anthropogenic Activities in Bahrain, Arabian Gulf," In: S. Hong-Bo, Ed., Metal Contaminations: Sources, Detection and Environmental Impacts, NOVA Science Publishers, Inc. New York, 2012, pp. 157-175.

[35] R. Riera, F. Tuya, E. Ramos, M. Rodriguez and O. Monterroso, "Variability of Macrofaunal Assemblages on the Surrounding of a Brine Disposal," Desalination, Vol. 291, 2012, pp. 94-100. doi:10.1016/j.desal.2012.02.003 